atoms when they received these waves, after accumulating energy of the right frequency, flung it away in a minute fraction of a second and thereby stimulated the nerves. The stimulation was much greater than the light which fell upon the eye, which was marvellously sensitive to light, but to no other kind of vibration. He would like an experiment to be made with the retina of an eye, if such experiment were possible with a dead eye. He would like to put the retina on an electroscope, then illuminate with red, green, or violet light, to see whether it would shoot off electrons and stimulate the electroscope. It would be a very delicate experiment, but they had very delicate instruments now.

\title{
The Ophthalmic Service in the American Expeditionary Forces
}

An authoritative history of the ophthalmic service in the American Expeditionary Forces was presented to the Section on Ophthalmology of the American Medical Association, by Dr. Allen Greenwood, senior consultant, on June 11, 1919 (See Amer. Jl. Ophthal., August, 1919.) It forms instructive and interesting reading. Dr. Greenwood was appointed senior consultant in ophthalmology in May, 1918, and in that month and the following he visited many of the French hospitals belonging to the A.E.F. The then conditions of those institutions are outlined in the paper before us. Much was done in seeing that the hospitals were properly equipped for eye work and setting aside certain of them for special purposes. In October, 1918, the senior consultant visited all similar institutions in England, and made suggestions upon what he saw to the American authorities. His headquarters in France were in Neufchâteau, where his colleagues were Lieut.-Col. G. S. Derby, as assistant consultant, and Lieut.-Col. Nelson M. Black, as consultant. The office of the division of ophthalmology was established at "Neufchâteau. An important and useful duty of the office/was to visit various eye clinics, and to encourage the officers employed there. Circulars for the guidance of ophthalmologists were issued from time to time by the senior consultant, and in this way useful information was disseminated about "gassed" eyes, injuries of the eye, panophthalmitis, orbital injuries, brain injuries, trachoma, refraction cases, the keeping of records, the conservation of pathological specimens, the technic of Frost's operation, and so forth. An optical base and eight auxiliary units, each having an authorized strength of one officer and thirty-six men, were organized at Camp Crane, Allentown, Pa., in March, 1918, and left the United States on April 4, 1918. They arrived in France on May 4, 1918. Nineteen tons of optical machinery were shipped from America before 
the men left for France, but on the arrival of the units the position of the consignment could not be located, and this led to a delay of nearly two months in the work. Meanwhile, facilities were afforded for a number of the members of the base unit to work in the shop of Messrs. E. B. Meyrowitz. The buildings for the A.E.F., which were situated first at Neuilly and afterwards at Porte St. Cloud, were in full operation on October 1, 1918. The machinery and equipment were based upon the approximate production of one hundred pairs of glasses a day. From July 27, 1918, to December 1, 1918, 21,828 prescriptions were filled, not to mention smoked spectacles and repair jobs. The unusual nature of the prescriptions caused many complications, and necessitated the manufacture of special tools and gauges. But 50 per cent. of the prescriptions received averaged spherical from 2.00 to $5.00 \mathrm{D}$., in combination with cylinders from 1.5 to $5.00 \mathrm{D}$. Optical units were assigned to seven of the more important base hospitals and to one camp hospital. More were available as they arrived from the United States. The writer expresses his opinion that the optical units, although more or less experimental, proved their value to expeditionary forces. The cessation of hostilities rendered nugatory the proposal for mobile optical units. The number of American soldiers totally blinded from battle injuries is under one hundred, and it is most satisfactory to note that a serious attempt was made to carry out their preliminary education in France before removal to the United States.

As the result of his experience, Greenwood makes recommendations for the organization of an ophthalmic service. During the past campaign there was on numerous occasions a shortage of men capable of, undertaking eye work. The need was so obvious that the chief surgeon, on the recommendation of the senior consultant, cabled the request that an ophthalmic surgeon be attached to all evacuation hospitals sent over from America in the future. No eye surgery should be done in the field hospital, and only minor cases should be retained in them. On an emergency the advice of an eye surgeon can be obtained from the nearest mobile or evacuation or base hospital. An ophthalmologist should be attached to every mobile hospital, which should be equipped to deal with eye surgery. All ophthalmic surgeons attached to mobile and evacuation hospitals should be prepared to undertake other duties in addition to their own proper work. Mobile hospitals need not be fitted for refraction cases. An evacuation hospital, on the other hand, should be fitted to deal with all varieties of eye work, and, of course, be provided with a trial case of lenses, and a hand perimeter with charts. Base hospitals should be provided with an ophthalmic surgeon, and be fully equipped. Where justified by the amount of work, the eye 
service should be separated from the ear, nose, and throat departments. Where several hospitals are close together, one should be selected to receive all eye cases, and in a similar way the several ophthalmic surgeons can be grouped. Such a plan was carried out in Base Hospital 36 for the Vittel and Contrexèville areas, and in Base Hospital 46 for the Bazoilles group. A permanent record of refraction done at home should accompany the soldier going abroad, and in the case of officers is best carried with his personal papers and pasted inside the cover of the soldier's pay book. The instrumental equipment is specified, and we note that the Lancaster type of magnet is alone included in the list.

\section{ABSTRACTS}

\section{I.-MYOTONIC DYSTROPHY}

Fleischer, Bruno (Tübingen).-Myotonic dystrophy (myotonia atrophica) with cataract. (Ueber myotonische Dystrophie mit Katarakt.) Arch. f. Ophthal., Vol. XCVI., parts i and ii., I918.

Fleischer here gives a careful account of myotonic dystrophy, of which thirty-eight cases have been observed in the Tübingen Clinic since 1901, with special reference to the occurrence of cataract. He gives in tabular form an analysis of his cases according to the various symptoms, as well as a number of tables to illustrate the hereditary nature of this affection.

The author sums up his remarks as follows:

Pre-senile cataract appearing at the age of 25 to 45 years is frequently a symptom of this disease.

The disease is distinguished by muscular and general symptoms, atrophy of certain muscles of the head and neck, forearms, and small muscles of the hand, extending later to the lower extremities, trunk, and finally affecting the musculature of almost the entire body, and myotony in the muscles of the hand, tongue, and jaw; atrophy or degeneration of the thyroid glands, general emaciation, atrophy of the pharyngeal muscles with consequent disturbance of speech and deglutition, cataract, vasomotor disturbances, baldness in males, atrophy of testicles, sexual disturbances in both sexes, and mental and moral deterioration.

This affection is steadily progressive, it rarely begins before the age of 25 and usually before the fiftieth year, leads to death, which not infrequently supervenes at a much earlier date from intercurrent disease. In the cases associated with cataract, it appears in females most frequently between the ages of 25 and 35, and in males 